\title{
Video Article \\ A Simple and Efficient Method to Isolate Macrophages from Mixed Primary Cultures of Adult Liver Cells
}

\author{
Hiroshi Kitani ${ }^{1}$, Takato Takenouchi ${ }^{1}$, Mitsuru Sato ${ }^{1}$, Miyako Yoshioka ${ }^{2}$, Noriko Yamanaka ${ }^{2}$ \\ ${ }^{1}$ Transgenic Animal Research Center, National Institute of Agrobiological Sciences, Tsukuba, Japan \\ ${ }^{2}$ Safety Research Team, National Institute of Animal Health, Tsukuba, Japan
}

Correspondence to: Hiroshi Kitani at kitani@affrc.go.jp

URL: https://www.jove.com/video/2757

DOI: doi:10.3791/2757

Keywords: Infection, Issue 51, macrophage-like cells, proliferation, hepatocytes, mixed culture, shaking, attachment

Date Published: 5/24/2011

Citation: Kitani, H., Takenouchi, T., Sato, M., Yoshioka, M., Yamanaka, N. A Simple and Efficient Method to Isolate Macrophages from Mixed Primary Cultures of Adult Liver Cells. J. Vis. Exp. (51), e2757, doi:10.3791/2757 (2011).

\section{Abstract}

Kupffer cells are liver-specific resident macrophages and play an important role in the physiological and pathological functions of the liver ${ }^{1-3}$. Although the isolation methods of liver macrophages have been well-described ${ }^{4-6}$, most of these methods require sophisticated equipment, such as a centrifugal elutriator and technical skills. Here, we provide a novel method to obtain liver macrophages in sufficient number and purity from mixed primary cultures of adult rat liver cells, as schematically illustrated in Figure 1.

After dissociation of the liver cells by two-step perfusion method ${ }^{7,8}$, a fraction mostly composed of parenchymal hepatocytes is prepared and seeded into T75 tissue culture flasks with culture medium composed of DMEM and 10\% FCS.Parenchymal hepatocytes lose the epithelial cell morphology within a few days in culture, degenerate or transform into fibroblast-like cells (Figure 2). As the culture proceeds, around day 6, phase contrast-bright, round macrophage-like cells start to proliferate on the fibroblastic cell sheet (Figure 2). The growth of the macrophage-like cells continue and reach to maximum levels around day 12 , covering the cell sheet on the flask surface. By shaking of the culture flasks, macrophages are readily suspended into the culture medium. Subsequent transfer and short incubation in plastic dishes result in selective adhesion of macrophages(Figure 3), where as other contaminating cells remain suspended. After several rinses with PBS, attached macrophages are harvested. More than $10^{6}$ cells can be harvested repeatedly from the same T75 tissue culture flask at two to three day intervals for more than two weeks(Figure 3).The purities of the isolated macrophages were 95 to $99 \%$, as evaluated by flow cytometry or immunocytochemistry with rat macrophage-specific antibodies (Figure 4). The isolated cells show active phagocytosis of polystylene beads (Figure 5), proliferative response to recombinant GM-CSF, secretion of inflammatory/anti-inflammatory cytokines upon stimulation with LPS, and formation of multinucleated giant cells ${ }^{9}$.

In conclusion, we provide a simple and efficient method to obtain liver macrophages in sufficient number and purity without complex equipment and skills. This method might be applicable to other mammalian species.

\section{Video Link}

The video component of this article can be found at https://www.jove.com/video/2757/

Protocol

\section{Perfusion of the Liver}

1. Anesthetize an adult male Sprague-Dawley rat (at 10 to 15 weeks-old; body weight $150-200 \mathrm{~g}$ ) by an intraperitoneal injection of a sodium pentobarbital solution ( $50 \mathrm{mg}$ sodium pentobarbital / $\mathrm{kg}$ body weight).

2. Place the animal in a stainless pan and spray $70 \%$ ethanol onto its abdomen and thorax.

3. Make a small cut and peel off the skin. Open the abdomen by the cut with a pair of scissors.

4. Confirm the location of portal vein, pass a surgical thread under the portal vein and loosely clump.

5. Clump the distal part of the inferior vena cava and mesenteric vein to prevent blood reflux into the liver. Open the thoracic cavity by cutting the diaphragm with scissors, and expose the heart.

6. Insert a plastic catheter ( $2 \mathrm{~mm}$ diameter) into the portal vein and tighten the thread firmly around the catheter.

7. Connect the catheter to a perfusion system which is loaded with washing solution $\left(\mathrm{Ca}^{2+}-\mathrm{Mg}^{2+}\right.$ free HBSS containing $0.5 \mathrm{mM}$ EGTA, 10 mM HEPES and $4.2 \mathrm{mM} \mathrm{NaHCO} 3 ; \mathrm{pH} 7.2$ ) prewarmed at $37^{\circ} \mathrm{C}$.

8. Begin perfusion in situ at a rate of $10 \mathrm{ml} / \mathrm{min}$. At the same time, make a cut in right atrium wall. Continue perfusion for $10 \mathrm{~min}$.

9. Switch the perfusion solution to collagenase solution [HBSS containing $10 \mathrm{mM} \mathrm{HEPES}$ and $4.2 \mathrm{mM} \mathrm{NaHCO}{ }_{3}$ supplemented with Type I collagenase $(0.05 \%)$ and trypsin inhibitor $(50 \mu \mathrm{g} / \mathrm{ml}) ; \mathrm{pH} 7.5]$, and perfuse for $10-20 \mathrm{~min}$ at a rate of $10 \mathrm{ml} / \mathrm{min}$ until the liver slightly swells and shows the sign for disintegration of the liver structure under serous membrane. 


\section{Preparation of Parenchymal Hepatocyte-rich Cell Fraction}

1. Remove and carefully transfer the liver into a sterile beaker containing $25 \mathrm{ml}$ of collagenase solution. Mince into small pieces by scissors.

2. Add $75 \mathrm{ml}$ of cold MEM into the resultant cell suspension. After gentle pipetting, filtrate through a cell strainer (100 $\mu \mathrm{m})$ to remove connective tissues and undigested tissue fragments.

3. Transfer the filtrate into $50 \mathrm{ml}$ conical tubes and centrifuge at $50 \times \mathrm{g}$ for $1 \mathrm{~min}$ at $4^{\circ} \mathrm{C}$ (brake off).

4. Carefully discard the supernatant. Resuspend the pellet with cold MEM.

5. Repeat 2.4) three times.

\section{Mixed Primary Culture of Liver Cells}

1. Suspend the cells obtained in 2.5) in the growth medium composed of DMEM containing $10 \%$ heat inactivated FCS, supplemented with $100 \mu \mathrm{M} \beta$-mercaptoethanol, $10 \mu \mathrm{g} / \mathrm{ml}$ insulin, $100 \mu \mathrm{g} / \mathrm{ml}$ streptomycin and $100 \mathrm{U} / \mathrm{ml}$ penicillin, and seed into five to ten tissue culture flasks (surface area: $75 \mathrm{~cm}^{2}$ ) at a density of $6.7 \times 10^{4}$ cells $/ \mathrm{cm}^{2}\left(5 \times 10^{6}\right.$ cells / flask $/ 12-15 \mathrm{ml}$ of medium).

2. Incubate the culture flasksat $37^{\circ} \mathrm{C}$ in an atmosphere of $5 \% \mathrm{CO}_{2}-95 \%$ air.

3. Replace the growth medium every 2 to 3 days intervals.

\section{Selective Isolation of Macrophages}

1. After 12 days of culture, macrophages proliferate on the cell sheet. These cells are suspended by reciprocal shaking of the culture flasks at 80 - 120 strokes per minute for $30 \mathrm{~min}$ at $37^{\circ} \mathrm{C}$.

2. Transfer the culture medium into $100 \mathrm{~mm}$ non-tissue culture grade plastic dishes. Pool the medium from two T75 flasks into one plastic dish. Refill culture flasks with the growth medium and return them to the incubator.

3. Incubate plastic dishes for $30 \mathrm{~min}$ at $37^{\circ} \mathrm{C}$ in an atmosphere of $5 \% \mathrm{CO}_{2}-95 \%$ air. Macrophages readily attach to non-tissue culture grade plastic dishes under this incubation process, whereas other contaminating cells do not.

4. Aspirate the medium and gently rinse the plastic dish with PBS. Repeat this step three times.

5. Add $1 \mathrm{ml}$ of TrypLE Express solution into the dish, and incubate for $10 \mathrm{~min}$ at $37^{\circ} \mathrm{C}$ in an atmosphere of $5 \% \mathrm{CO}_{2}-95 \%$ air.

6. Add $9 \mathrm{ml}$ of the growth medium. Gently scrape off the attached macrophages by a cell scraper.

7. Transfer the cell suspension into a $15 \mathrm{ml}$ conical tube and centrifuge at $180 \mathrm{xg}$ for $5 \mathrm{~min}$ at $25^{\circ} \mathrm{C}$ (brake on).

8. Discard the supernatant and add $1 \mathrm{ml}$ of the growth medium. Dissociate into single cells by vigorous pipetting. Enumerate the cell number by a hemocytometer-counting.

9. Isolation steps can be repeated with the same culture flasks at two to three day intervals for more than two weeks.

10. Isolated macrophages can be cultured in the growth medium described in 3.1 .

\section{Representative Results}

An example of a mixed primary culture of adult rat liver cells is shown in Figure 2. Parenchymal hepatocytes lose the epithelial cell morphology within a few days in culture, degenerate or transform into fibroblast-like cells. Then, around day 6 to 12, phase contrast-bright, round macrophage-like cells vigourouly proliferate on the fibroblastic cell sheet. By shaking of the culture flasks, macrophages are readily suspended into the culture medium, and subsequent transfer and incubation in plastic dishes result in selective adhesion of macrophages(Figure 3). The macrophage-like cells can be harvested as early as day 8 , and the numbers reached maximal levels on days 12 to 14 . More than $10^{6}$ cells can be harvested from a T75 culture flask repeatedly at 2 to 3 day intervals for more than two weeks, enabling a total cell yield per flask of $10^{7}$ per T75 culture flask (Figure 3). The purities of the isolated macrophages were 95 to $99 \%$, as evaluated by flowcytometry or immunocytochemistry with rat macrophage-specific antibodies, such as ED-1 (Figure 4), ED-3, OX-41 (Figure 4) and Iba $1^{9}$.The isolated cells show typical characteristics of macrophages, such as active phagocytosis of polystylene beads (Figure 5), proliferative response to recombinant GM-CSF, secretion of inflammatory/anti-inflammatory cytokines upon stimulation with LPS, and formation of multinucleated giant cells ${ }^{9}$. 


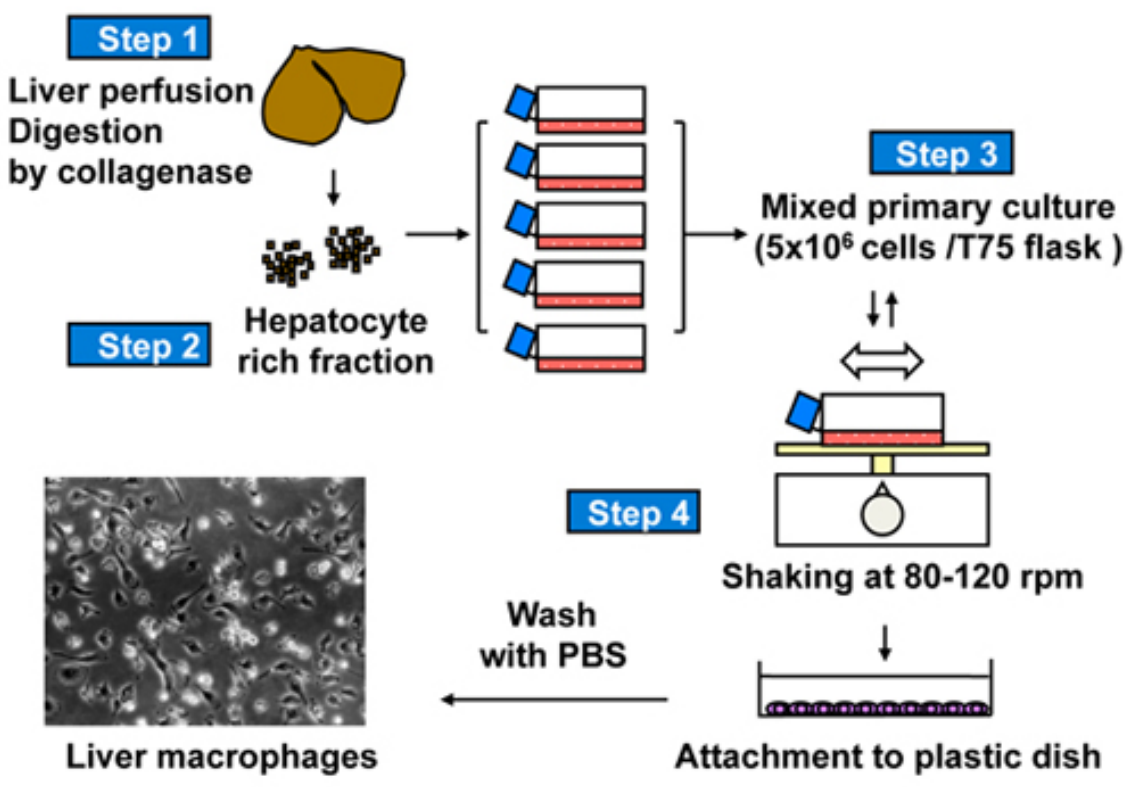

Figure 1. A scheme for selective isolation and purification of macrophage-like cells from mixed primary culture of rat liver cells.

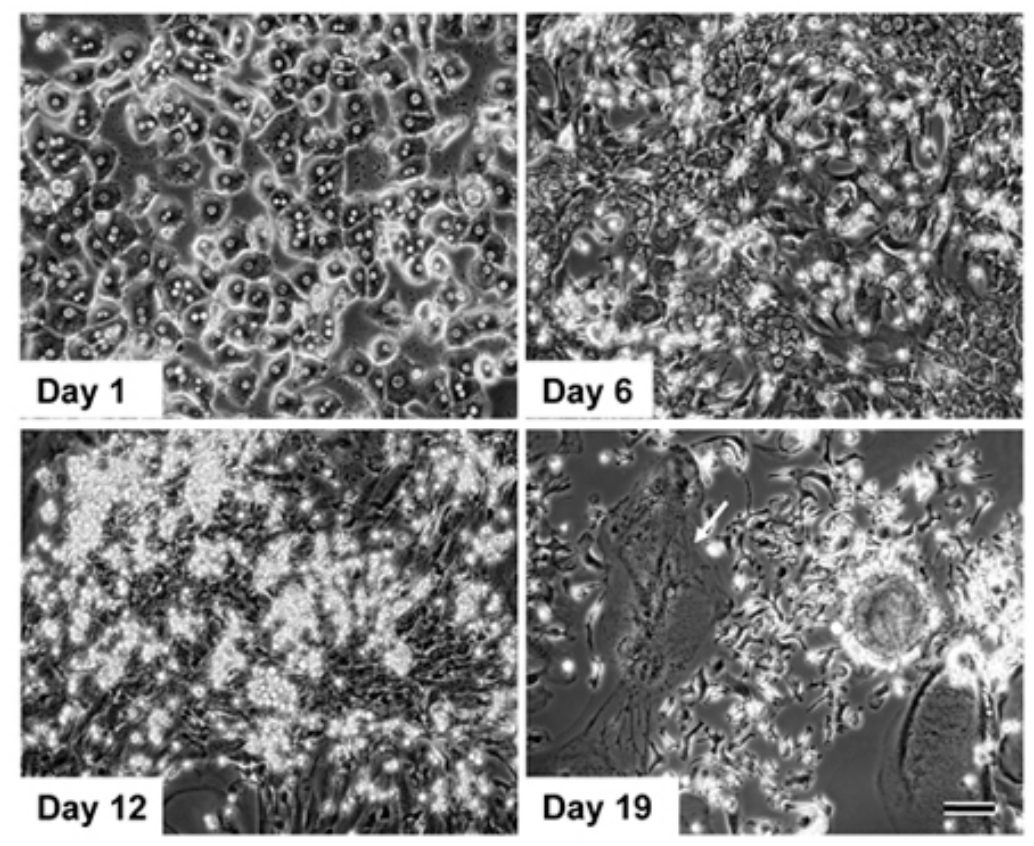

Figure 2. Primary culture of rat liver cells and proliferation of macrophage-like cells. Arrow indicates a multinuclear giant cell. Scale bar $=100$ $\mu \mathrm{m}$. Reprinted from the Journal of Immunological Methods, Vol.360, 47-55 (2010) ${ }^{9}$ with permission from Elsevier. 

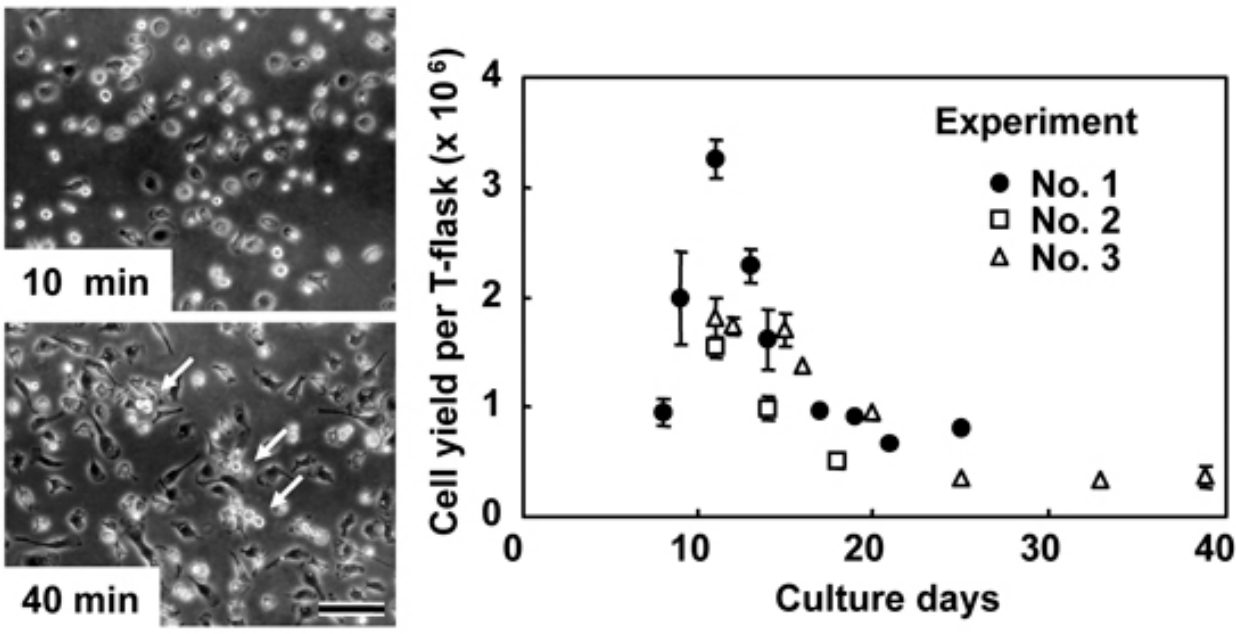

Figure 3. Selective isolation of macrophage-like cells by the shaking and attachment method. Cells were suspended into the culture medium by shaking the flasks, subsequently transferred into non-tissue culture grade plastic dishes, and incubated at $37^{\circ} \mathrm{C}$. As early as 10 min after plating, macrophage-like cells attached to the dish surface, while other contaminating fibroblastic cells remained suspended. After rinsing with PBS, a highly purified macrophage population was obtained. These cells gained typical macrophage morphology after 40 min of culture, and mitotic cells were frequently observed (arrows). Subsequent changes in cell numbers recovered from flasks at different culture periods are shown. Values are an average $\pm S D$ from three to five flasks. Experiments were repeated three times and data are indicated by different symbols. Scale bar $=100$ $\mu \mathrm{m}$. Reprinted from the Journal of Immunological Methods, Vol.360, 47-55 (2010) ${ }^{9}$ with permission from Elsevier.
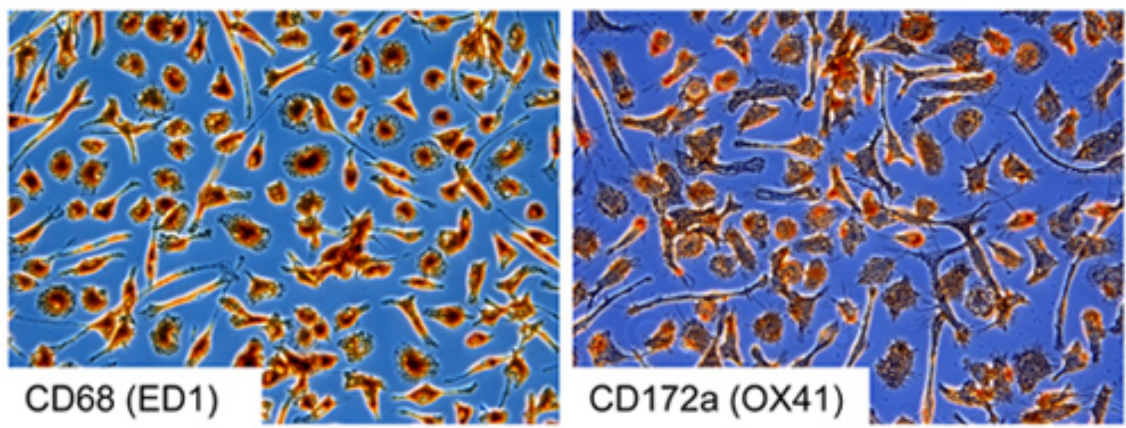

Figure 4. Immunocytochemical staining of macrophage-like cells with monoclonal antibodies against rat macrophages.
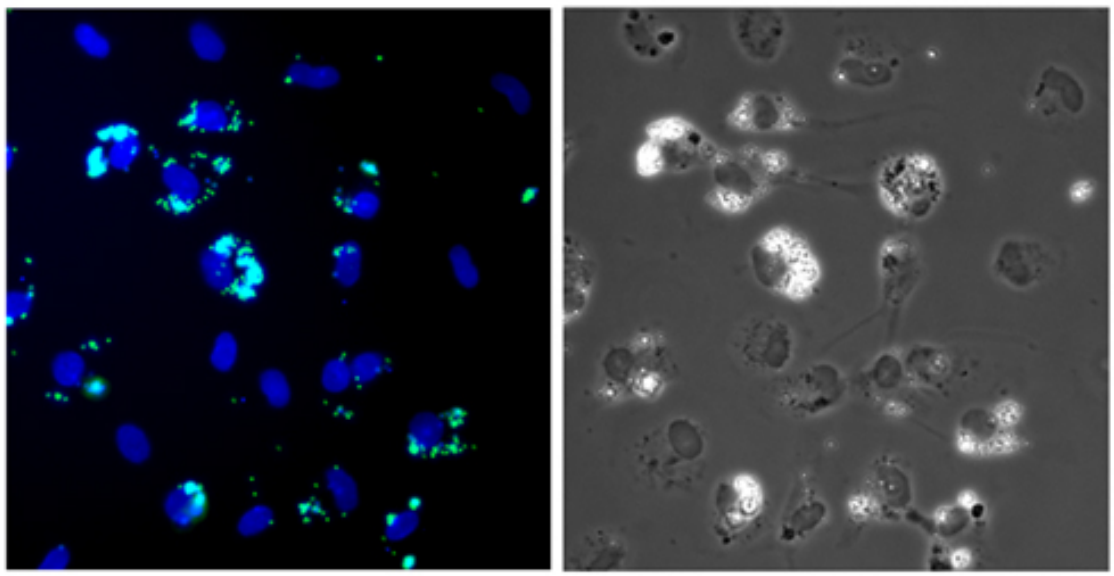

Blue = DAPI; Green = FITC beads

Figure 5. Phagocytosis of FITC-labeled microbeads by macrophage-like cells. 


\section{Discussion}

Here, we report a simple and efficient method to obtain macrophages from the mixed primary cultures of adult rat liver cells. Our method relies first on the novel proliferative activity of macrophages in the mixed culture of rat liver cells, and then subsequent isolation and purification of these cells on the basis of their biological characteristics as macrophages ${ }^{9}$. It may be possible the macrophages proliferated in the mixed primary culture of adult liver cells might have originated from Kupffer or related cells that contaminated into the parenchymal hepatocytes fraction. The macrophages might have responded to specific environmental changes caused by transformation of parenchymal hepatocyte ${ }^{10}$ and other fibroblastic cells in the mixed primary cultures.

In conclusion, our method provides isolation of macrophage-like cells in sufficient number and purity from the primary culture of rat liver cellswithout using sophisticated equipment and technical skills. In addition, the isolation procedure can be repeated with the same culture flask for more than two weeks. This method might be applicable to other mammalian species.

\section{Disclosures}

All animals were kept and operated in the animal facility in the National Institute of Animal Health, according to the guidelines and regulations set forth by the Institution's Committee for animal experiments.

\section{Acknowledgements}

This work was funded by a research grant and a Grant-in-Aid from the Food Nanotechnology Project of the Ministry of Agriculture, Forestry, and

Fisheries of Japan.

\section{References}

1. Crispe, I.N. The liver as a lymphoid organ. Annu. Rev. Immunol. 27, 147-163 (2009).

2. Roberts, R.A., et al. Role of the Kupffer cell in mediating hepatic toxicity and carcinogenesis. Toxicol. Sci. 96, 2-15 (2007).

3. Gao, B., Jeong, W.I. \& Tian, Z. Liver: An organ with predominant innate immunity. Hepatology 47, 729-736 (2008).

4. Janousek, J., Strmen, E. \& Gervais, F. Purification of murine Kupffer cells by centrifugal elutriation. J. Immunol. Methods 164, 109-117 (1993).

5. Olynyk, J.K. \& Clarke, S.L. Isolation and primary culture of rat Kupffer cells. J. Gastroenterol. Hepatol. 13, $842-845$ (1998).

6. Heuff, G., Meyer, S. \& Beelen, R.H. Isolation of rat and human Kupffer cells by a modified enzymatic assay. J. Immunol. Methods 174, $61-65$ (1994).

7. Seglen, P.O. Preparation of isolated rat liver cells. Methods Cell Biol. 13, 29-83 (1976).

8. Yoshioka, M., et al. Primary culture and expression of cytokine mRNAs by lipopolysaccharide in bovine Kupffer cells. Vet. Immunol. Immunopathol. 58, 155-163 (1997).

9. Kitani, H., Takenouchi, T., Sato, M., Yoshioka, M. \& Yamanaka, N. A novel isolation method for macrophage-like cells from mixed primary cultures of adult rat liver cells. J. Immunol. Methods 360, 47-55 (2010).

10. Gorrell, M.D. Liver fibrosis: the hepatocyte revisited. Hepatology 46, 1659-1661 (2007). 